\title{
Characterization of Some Plant Growth-Promoting Rhizobacteria Isolated from Sugar Beet Rhizosphere
}

Mahmoud M. Abdel-Hakim, O. F. Dakhly and A. M. Sameh*

Genetics Department, Faculty of Agriculture, Minia University, Minia, Egypt

*Corresponding author: ahmed8881@ s-mu.edu.eg; Tel: +01111437241 .

\section{Article information}

Received: 28 June 2021

Revised: 12 August 2021

Accepted: 29 August 2021

\section{Key words}

Antagonistic

Activity

Rhizobacteria

Phytomicrobiome

Sugar beet.

\begin{abstract}
Plant growth promoting rhizobacteria (PGPR) are the rhizosphere bacteria that can be used to perform important functions such as increasing plant growth and protecting from several diseases caused by plant pathogens. This study aimed to characterize the native PGPR strains isolated from sugar beet rhizosphere and to evaluate their antagonistic activity against three of the common phytopathogen. Therefore, thirty bacterial strains were isolated from sugar beet rhizosphere and some of their morphological characteristics were investigated. Enzymatic (catalase, gelatinase \& amylase) activities reflected a high degree of variability amongst strains. The antibiotic resistance to seven different antibiotics were significantly varied as revealed by zone-diameter around antibiotic disk. In vitro antagonistic activity against $F$. solani, $F$. oxysporium and $R$. solani, revealed a considerable diversity of antagonism. Many isolates were significantly reduced mycelial growth of $F$. solani $(57 \%)$. Some isolates showed a good degree of antagonism against $F$. oxysporium $(60 \%)$ while such activity against $R$. solani were varied from 0.0 to $56.5 \%$. Partial-length of $16 \mathrm{~S}$ rRNA gene ( $1200 \mathrm{bp}$ ) was amplified and sequenced from two isolates, AM-15 and AM-26, that displayed a substantial antagonistic activity against studied pathogens. Nucleotide BLAST of AM-26 16S rRNA sequence showed the highest similarity $(>99.5 \%)$ to many Pseudomonas chlororaphis subsp. aurantiaca, Pseudomonas chlororaphis \& Pseudomonas sp. strains. However, AM-26 16S rRNA partial sequence shared a high similarity $(>99.63 \%)$ with its corresponding sequence of Bacillus subtilis strain RRLKE01 (ACNO KF029595.1) and 99.54\% similarity were detected with many other Bacillus subtilis and Bacillus sp. strains as well.
\end{abstract}

\section{Introduction}

A plant growing under field conditions is always associated with many microbial populations [1\& 2]. These populations of phytomicrobiome are associated with every plant tissue and able to provide a wide range of services and benefits to the plant [3]. Most of these plants have the ability to carefully regulate the activity of the associated bacterial community. Phytomicrobiome includes many specialized microbial groups, whether bacteria or fungi including those living in the thin soil layer directly surrounding the root which is called rhizomicrobiome [4].

Rhizobacteria is one of the most important microbial categories in the rhizomicrobiome group that can colonize the surfaces of roots in the soil [5]. Rhizobacteria having positive influence on plant health are referred to as plant growth-promoting rhizobacteria (PGPR) [6]. The PGPR plays a vital role in plant disease management to promote cyclic productivity through antagonism between the bacteria and soil-borne pathogens by production of inhibitory compounds and hydrolytic enzymes that are often active against a broad spectrum of phytopathogens [7\& 8]. In addition, microbes of the rhizobacteria play key roles in diazotrophic fixation of nitrogen [9], solubilization of phosphate and other nutrients [10], siderophores [11], improving soil texture, nutrient acquisition, modulating extracellular molecules such as hormones secretion [12], secondary metabolites, antibiotics, and various signal compounds, all leading to plant growth stimulation, biocontrol and improve crop tolerance for the abiotic stresses [13\& 14].

There are many bacterial genera that belong to the rhizobacteria have been shown to be mostly diverse strains of Bacillus and Pseudomonas spp. [15]. There are also other genera like Enterobacter, Azoarcus, Serratia, Rhizobium spp. and Streptomyces. Species of these genera which are represents the main source of endophytic colonizers are commonly found in the soil/rhizosphere [16].

Sugar beet (Beta vulgaris L.) is considered one of the newest and most important sugar crops in Egypt belonging to the Chenopodiaceae family. This important crop contributes around 1.3 million tons of sugar, representing $56.5 \%$ from the local production [17] thus, classified as the second important sugar crop in Egypt after sugar cane. The plant species is native to the Mediterranean region, but beets have been cultivated in temperate regions for a long time mainly as a source of sweets [18]. There are some reports of microorganisms associated with sugar beet that focus mainly on bacteria [19]. All studies indicate a high rate of colonization of sugar beet plant by microorganisms including seeds [20]. 
Sugar beet is highly susceptible to several soil-borne fungi that attack this crop causing a significant reduction in production. There are many fungi that negatively affect the quality and quantity of the crop such as Rhizoctonia solani, Fusarium solani, Fusarium oxysporum f. sp. and Macrophomina phaseolina [21]. Fusarium is a complex genus of ascomycete fungi that consists of plant pathogens of agricultural relevance. Controlling Fusarium infection in crops that leads to substantial yield losses is challenging. These economic losses along with environmental and human health concerns over the usage of chemicals in attaining disease control are shifting focus toward the use of biocontrol agents for effective control of phytopathogenic Fusarium spp. [19, 22 \& 23].

Rhizoctonia solani is classified as one of the most damaging sugar beet pathogens that cause post-harvest losses in storage piles as well as being the main cause of root rot and Rhizoctonia crown disease [24]. This is related to the fact that it is a pathogen characterized by high aggressiveness against sugar beet, high tolerance to high and low temperatures, and low sensitivity to fungicides [25]. One of the potential tactics to resist these diseases are the use of rhizobacterial inoculation of sugar beet seeds to increase the plant resistance. However, the plant-growth promoting and biocontrol efficacy of PGPR often depend upon the rhizosphere competence of the microbial inoculants [26]. The objectives of the present study were to isolate and characterize bacterial strains from sugar beet rhizosphere. Therefore, morphological, biochemical attributes as well as genetical identification were conducted using $16 \mathrm{~S}$ rRNA. Moreover, the antagonistic effects of these isolates, against three of the most important fungi that attack this crop causing a significant reduction in production, were evaluated.

\section{Materials and Methods}

\section{Collection of rhizospheric soil sample}

Root and its adherent soil samples were randomly collected from rhizosphere of sugar beet from cultivated area in Mallawi, El-Minia governorate, Egypt. Soil and roots samples were collected after 32 days of planting and placed in plastic bags.

\section{Isolation of rhizobacteria from sugar beet rhizosphere}

To isolate rhizospheric bacteria from sugar beet, soil samples were collected from the most outer layer from roots of sugar beet (rhizoplane) with their clay (rhizosphere) as described by Islam et al. [14]. Bacterial colonies distinguished in shape and texture were selected and purified for further purification. Single colonies of the purified isolates were cultured on slant agar medium, stored at $2^{\circ} \mathrm{C}$ and sub-cultured regularly for longterm storage.

\section{Morphological and Biochemical characterization}

Morphological characteristics of each isolate were checked out on PDA agar plates at $28 \pm 2^{\circ} \mathrm{C}$, as described by Somasegaran and Hoben [27]. The Gram's reaction (negative or positive) was performed, to determine stain ability of bacterial isolates, as described by Vincent and Humphrey [28].

Bacterial motility was performed by the SIM (HydrogenSulfide, Indole, Motility) test [29] to determine the ability of bacterial isolates to migrate away by using flagella from the spot of inoculation (motile or non-motile). Each isolate was spot-inoculated on the center of semi-solid nutrient agar plates $(0.2 \%$ agar $)$ and incubated at $30^{\circ} \mathrm{C}$. The diffusion of colony was observed and recorded after 24 hours.

Congo red testing was used to determine the presence and purity of rhizobium culture as defined by Berkhoff and Vinal [30]. Catalase test, that determine whether the rhizobacterial isolates are better suited to aerobic or anaerobic environments, was done as described by McFadden [29]. Phosphate solubilizing activity of bacterial isolates were tested in vitro in Pikovaskaya's medium containing tricalcium phosphate [31]

Intrinsic antibiotic resistances were tested in Nutrient Agar (NA) medium supplemented with one of the following antibiotics $(\mu \mathrm{g} / \mathrm{ml})$ : Chloramphenicol 30; Ceftriaxone 30; Fusidic acid 10; Streptomycin 10; Amoxicillin 30; Tetracycline 10 and Nitrofurantion 300 . The reactions to antibiotics were determined by the disc diffusion method [32]. Effects of antibiotic resistances were determined by measuring the distal zones diameter around antibiotic discs.

\section{Enzymatic activity of the bacterial isolates.}

The ability of bacteria to produce Gelatinases was determined by Gelatin hydrolysis test using a nutrient gelatin medium in which Gelatin serves as both solidifying agent and substrate for Gelatinase activity [33]. The ability of the present bacterial isolates to produce the extracellular enzymes, $\alpha$-amylase and oligo-1,6-glucosidase, was conducted by starch hydrolysis test according to using starch agar medium [34].

\section{In vitro evaluation of antagonistic activities of rhizobacteria}

Antifungal activity of rhizobacterial isolates against $F$. solani, $F$. oxysporum, and Rhizoctonia solani was screened using the dual-culture plate method [35] .The diameter of mycelium pathogen was measured in both directions and average was recorded and the percentages of inhibition on growth of the test pathogen was calculated by using the equation of [36]: $\mathrm{L}=(\mathrm{C}-$ $\mathrm{T}) / \mathrm{C} \times 100$, where $\mathrm{L}$ is the inhibition percentage; $\mathrm{C}$ is the radial growth of the pathogen in control and $\mathrm{T}$ is the radial growth of the pathogen in treatment. All in vitro antagonism assays were made in triplicate and repeated twice.

\section{Identification of bacterial isolate using 16S rRNA sequencing}

Total genomic DNA of selected bacterial strains was purified using GeneJET Genomic DNA Purification Kit (ThermoFisher ${ }^{\circledR}$, USA). The two universal eubacterial primers (forward primer: 5'-AGAGTTTGATCCTGGCTCAG-3') and (reverse primer: 5'-ACGGCTACCTTGTTACGACTT-3') were used to amplify nearly full-length $16 \mathrm{~S}$ rRNA gene [37]. Sequencing reaction of the purified PCR product was carried out using an ABI BigDye Terminator V3.1 cycle sequencing kit and ABI PRISM 3500 genetic analyzer (Applied Biosystem, USA). The 16S rRNA gene sequencing reads were edited and assembled using Sequencher (Gene Code Corporation, MI, USA). The relevant sequences were obtained using the nucleotide BLAST program (https://blast.ncbi.nlm.nih.gov/Blast.cgi) and aligned using ClustalW version1.8 [38]. 


\section{Statistical analyses}

Standard procedure was adopted for recording data and statistical analysis was performed using software SPSS program (Version 17) and Microsoft Office Excel 2010.

\section{Results and Discussion}

\section{Isolation and morphological characterization of rhizobacterial isolates}

In this study, thirty bacterial strains were successfully isolated from sugar beet rhizosphere and were designated as AM-1 through AM-30 (Table 1). The morphological characterization showed that, all isolates produced fast-growing colonies, round to irregular with high elevations; most of these isolates have smooth surfaces and the rest have rough surfaces. The vast majority of them were aerobic except nine of them (AM-2, AM6, AM-7, AM-13, AM-18, AM-20, AM-21, AM-27, and AM28) were anaerobic. All cells of the pure bacterial isolates were rod shaped but not AM-2, AM-4, AM-14, AM-20, AM-24, and AM-25 that were circular shaped as shown in Table 1. Only three isolates (AM-5, AM-10, and AM-23) were Gram negative while the other 27 isolates reacted positively to Gram staining. Likewise, the majority (95\%) of bacteria in samples taken from the rhizosphere were Gram-positive compared to samples taken from bulk soil under different types of management regimes [14 $\&$ 39]. Only one (AM-5) of the selected bacterial isolates produced white colony on NA medium supplemented with $0.05 \%$ Congo red.

As shown in Table (1), fifteen isolates were motile, while the remaining isolates were non-motile. Motility might be one of the required traits that support motile strains to move and to colonize roots. However, the high proportions of non-motile bacteria among the bacterial isolates from the root surface suggest that flagellar motility is not an absolutely necessary bacterial feature in colonization of plant roots. This is confirmed by Czaban et al. [40] who also stated that, the proportion of motile strains gradually increased from "rhizosphere", through "rhizoplane". On solid Pikovskaya medium, five isolates (AM-23, AM-24, AM-25, AM-29 and AM-30) shown clear phosphate solubility by formation sharp halo zones of $\mathrm{P}$ solubilization, among them AM-29 showed maximum zone followed by AM-30. In the same way, microorganisms capable of producing a clear zone due to Phosphate solubilization in the surrounding Pikovskaya medium were selected as potential phosphate solubilizers [41]. Moreover, the results of [42] stated the ability of eight out of 61 rhizobacterial isolates to solubilize phosphate.

\section{Biochemical characterization}

Biochemical characterization of all bacterial isolates and enzymatic activities of the isolates are tabulated in Table $(1 \&$ 2 ). For Catalase production, twenty-one of the tested isolates showed positive results while the other nine isolates (AM-2, AM-6, AM-7, AM-13, AM-18, AM-20, AM-21, AM-27, and AM-28) were negative (Table 1). These results evidently established that all aerobic isolates ( 21 isolates) have the ability to produce catalase enzyme but not the anaerobic isolates ( 9 isolates) exactly as confirmed by Yousten et al. [43] Moreover, these results might suggest the ability of the Catalase positive isolates to neutralise the toxic effects of $\mathrm{H} 2 \mathrm{O} 2$ and contribute in the protection of bacterial cells against plant ROS (reactive oxygen species), where catalase negatives are not as identified by Fouts et al. [44]. This is the important aspect that bacteria require to avoid cellular toxicity [45].

Table (1): Some microbiological, physiological and biochemical properties of the thirty potential PGPR isolated from sugar beet rhizosphere.

\begin{tabular}{|c|c|c|c|c|c|c|c|c|c|}
\hline 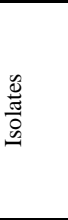 & 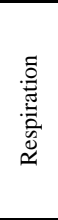 & 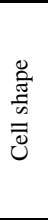 & 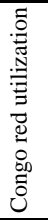 & 苞节 & 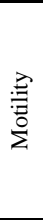 & 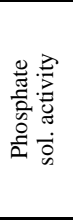 & 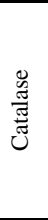 & 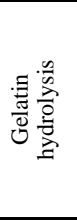 & 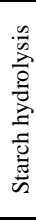 \\
\hline $\begin{array}{c}\text { AM- } \\
1\end{array}$ & Aer & $\mathrm{R}$ & - & + & + & - & + & - & + \\
\hline $\begin{array}{c}\text { AM- } \\
2\end{array}$ & Ana & $\mathrm{C}$ & - & + & - & - & - & + & + \\
\hline $\begin{array}{c}\text { AM- } \\
3\end{array}$ & Aer & $\mathrm{R}$ & - & + & + & - & + & + & + \\
\hline $\begin{array}{c}\text { AM- } \\
4\end{array}$ & Aer & $\mathrm{C}$ & - & + & + & - & + & + & + \\
\hline$\frac{\mathrm{AM}-}{5}$ & Aer & $\mathrm{R}$ & + & - & + & - & + & + & - \\
\hline $\begin{array}{c}\mathrm{AM}- \\
6\end{array}$ & Ana & $\mathrm{R}$ & - & + & + & - & - & + & - \\
\hline $\begin{array}{c}\text { AM- } \\
7\end{array}$ & Ana & $\mathrm{R}$ & - & + & + & - & - & + & + \\
\hline $\begin{array}{c}\text { AM- } \\
8\end{array}$ & Aer & $\mathrm{R}$ & - & + & + & - & + & + & - \\
\hline $\begin{array}{c}\text { AM- } \\
9\end{array}$ & Aer & $\mathrm{R}$ & - & + & - & - & + & + & + \\
\hline $\begin{array}{c}\text { AM- } \\
10\end{array}$ & Aer & $\mathrm{R}$ & - & - & + & - & + & + & + \\
\hline $\begin{array}{c}\text { AM- } \\
11\end{array}$ & Aer & $\mathrm{R}$ & - & + & + & - & + & + & - \\
\hline $\begin{array}{l}\text { AM- } \\
12\end{array}$ & Aer & $\mathrm{R}$ & - & + & + & - & + & + & - \\
\hline AM- & Ana & $\mathrm{R}$ & - & + & - & - & - & - & + \\
\hline $\begin{array}{c}\text { AM- } \\
14\end{array}$ & Aer & $\mathrm{C}$ & - & + & - & - & + & + & + \\
\hline $\begin{array}{c}\text { AM- } \\
15\end{array}$ & Aer & $\mathrm{R}$ & - & + & - & - & + & + & - \\
\hline $\begin{array}{c}\text { AM- } \\
16\end{array}$ & Aer & $\mathrm{R}$ & - & + & - & - & + & + & - \\
\hline $\begin{array}{c}\text { AM- } \\
17\end{array}$ & Aer & $\mathrm{R}$ & - & + & + & - & + & + & + \\
\hline $\begin{array}{c}\text { AM- } \\
18\end{array}$ & Ana & $\mathrm{R}$ & - & + & - & - & - & + & + \\
\hline $\begin{array}{c}\text { AM- } \\
19\end{array}$ & Aer & $\mathrm{R}$ & - & + & - & - & + & + & - \\
\hline $\begin{array}{c}\text { AM- } \\
20\end{array}$ & Ana & $\mathrm{C}$ & - & + & - & - & - & + & - \\
\hline $\begin{array}{c}\text { AM- } \\
21\end{array}$ & Ana & $\mathrm{R}$ & - & + & + & - & - & - & + \\
\hline $\begin{array}{l}\text { AM- } \\
22\end{array}$ & Aer & $\mathrm{R}$ & - & + & - & + & + & - & + \\
\hline $\begin{array}{l}\text { AM- } \\
23\end{array}$ & Aer & $\mathrm{R}$ & - & - & - & + & + & - & + \\
\hline $\begin{array}{c}\text { AM- } \\
24\end{array}$ & Aer & $\mathrm{C}$ & - & + & - & + & + & + & + \\
\hline $\begin{array}{c}\text { AM- } \\
25\end{array}$ & Aer & $\mathrm{C}$ & - & + & - & - & + & - & - \\
\hline $\begin{array}{c}\text { AM- } \\
26\end{array}$ & Aer & $\mathrm{R}$ & - & + & + & - & + & + & - \\
\hline AM- & Ana & $\mathrm{R}$ & - & + & - & - & - & + & + \\
\hline $\begin{array}{c}\text { AM- } \\
28\end{array}$ & Ana & $\mathrm{R}$ & - & + & + & - & - & - & - \\
\hline $\begin{array}{c}\text { AM- } \\
29\end{array}$ & Aer & $\mathrm{R}$ & - & + & - & + & + & + & + \\
\hline $\begin{array}{c}\text { AM- } \\
30\end{array}$ & Aer & $\mathrm{R}$ & - & + & + & + & + & + & - \\
\hline
\end{tabular}

Abbreviations: Aer: Aerobic, Ana: Anaerobic, R: Rod, C: circular, +: Positive Response, -: Negative response

The enzymatic activity of bacterial isolates was studied in relation to gelatinase and amylase as listed in Table (1). Twenty-three isolates were able to produce gelatinase into nutrient gelatin deep tubes while the other seven isolates (AM1, AM-13, AM-21, AM-22, AM-23, AM-25 and AM-28) were 
not. Concerning amylase production, thirteen isolates (Table 1) were not able to produce amylase enzyme into starch agar medium, while the rest of the isolates have the ability to do so as shown in Table (1) and Fig. (1). Accordingly, the isolates AM-25, AM-28 have the ability to produce both gelatinase and amylase.

\section{Antibiotic resistance}

The antibiotic resistance of the thirty PGPR isolated from sugar beet rhizosphere was tested on nutrient agar media supplemented with one of seven antibiotics (Nitrofurantion, Tetracycline, Amoxycillin, Streptomycin, Fusidin acid, Ceftriaxone and Chloramphenicol). Generally, the antibiotic resistance among the thirty isolates were varied from antibiotic to the other for all isolates as revealed by the Diameter (mm) of Zone (D/Z) around antibiotic disk (Table 2 and Fig. 1). Sensitivity varied amongst these isolates (weakly sensitive, $\mathrm{S}$; moderately sensitive, $\mathrm{S}+$ and highly sensitive, $\mathrm{S}++$ ) according to diameter distal to the antibiotic disk.

Out of the 30 isolates, one isolate (AM-4) showed high sensitivity to all antibiotics without exception, whereas isolates AM-11, AM-18, and AM-21 showed different degree of sensitivity to the antibiotics used in the present experiment. Isolate AM-2 was sensitive to Nitrofurantion, Streptomycin, and Fusidin acid, and highly sensitive to Tetracycline, Amoxicillin, and Ceftriaxone, while it was resistant to Chloramphenicol. In the same manner, isolate AM-27 showed high sensitivity to most antibiotics, sensitivity to Streptomycin and resistance to Ceftriaxone. Similarly, isolate AM-29 revealed high sensitivity to Tetracycline, Amoxicillin, and Chloramphenicol; sensitivity to Fusidin acid and Ceftriaxone; weak sensitivity to Streptomycin, and resistance to Nitrofurantion. Maximum zone of inhibition (39 mm) was observed in AM-11 isolate for Amoxycillin followed by tetracycline $(36 \mathrm{~mm})$. In the same style, minimum zone of inhibition $(5 \mathrm{~mm})$ was shown by AM-1 isolate for Nitrofurantion.

The variation in resistance and sensitivity of the bacterial isolates under study reveal the diverse of the potential plant growth promoting rhizobacterial strains of the sugar beet rhizosphere. Multiple antibiotic resistances shown by PGPR strains (e.g., isolates AM-5 and AM-14) might be associated with a high degree of tolerance to metals. Metal tolerance and antibiotic resistance have been reported by Wani et al. [46].

It has been suggested that under environmental conditions of metal stress, metal and antibiotic resistant microorganisms will adapt faster by the spread of R-factors than by mutation and natural selection [47]. With these considerations it can be concluded that resistant bacterial strains tolerate not only antibiotics but also heavy metals. Similar observations on antibiotics resistance by PGPR strains have been reported by Wani and Irene [48].
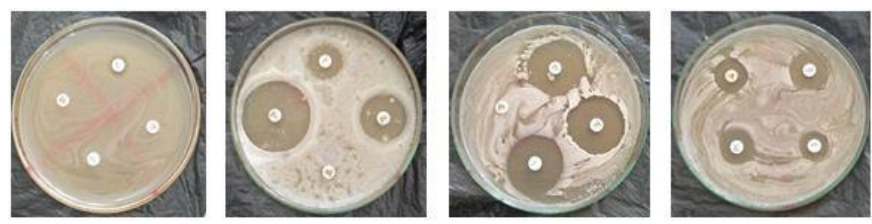

Figure(1): The Diameter ( $\mathrm{mm}$ ) of Zone (D/Z) around antibiotic disk presenting the effect of antibiotics on growth of some rhizobacterial isolates

Table (2): Tolerance of the thirty potential plant growth promoting rhizobacterial isolated from sugar beet rhizosphere to different antibiotics.

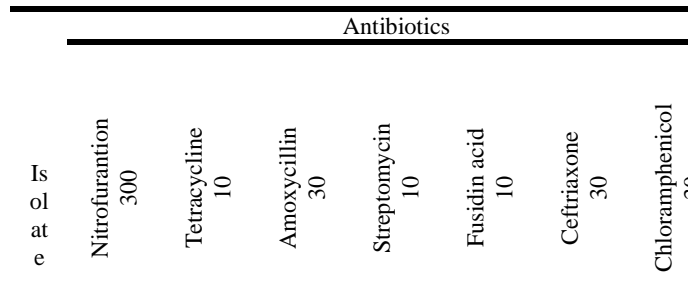

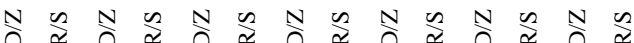

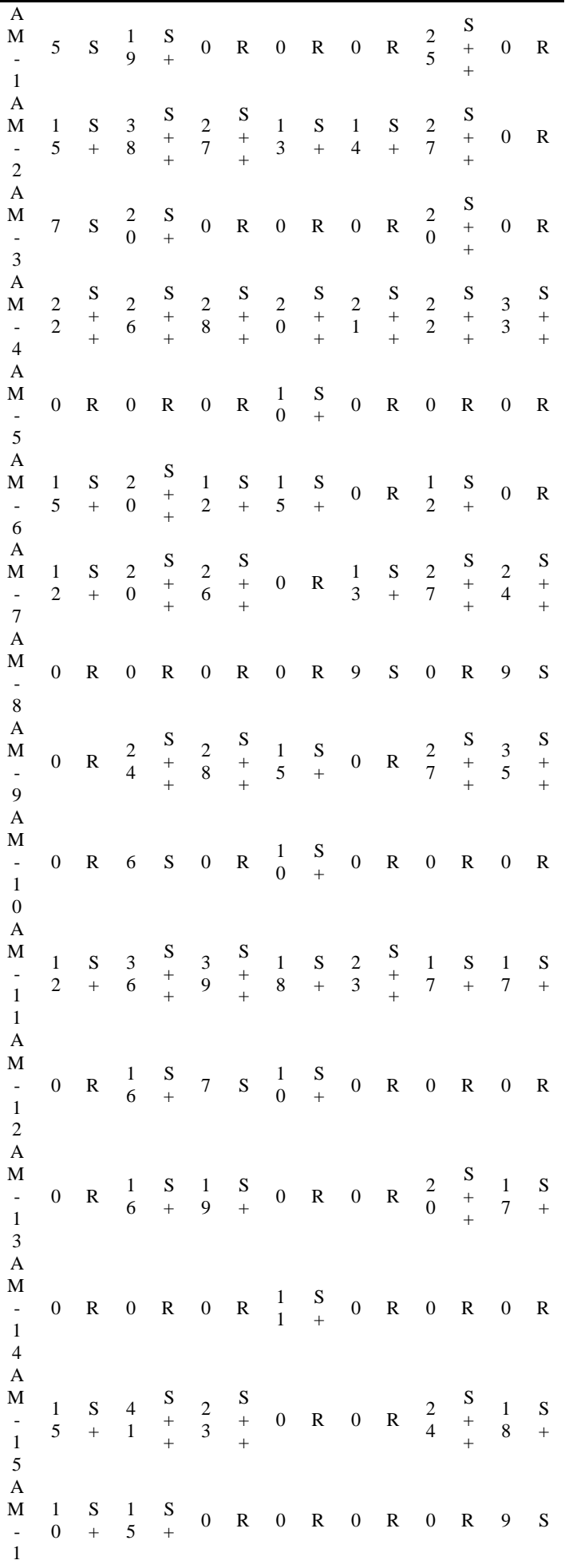




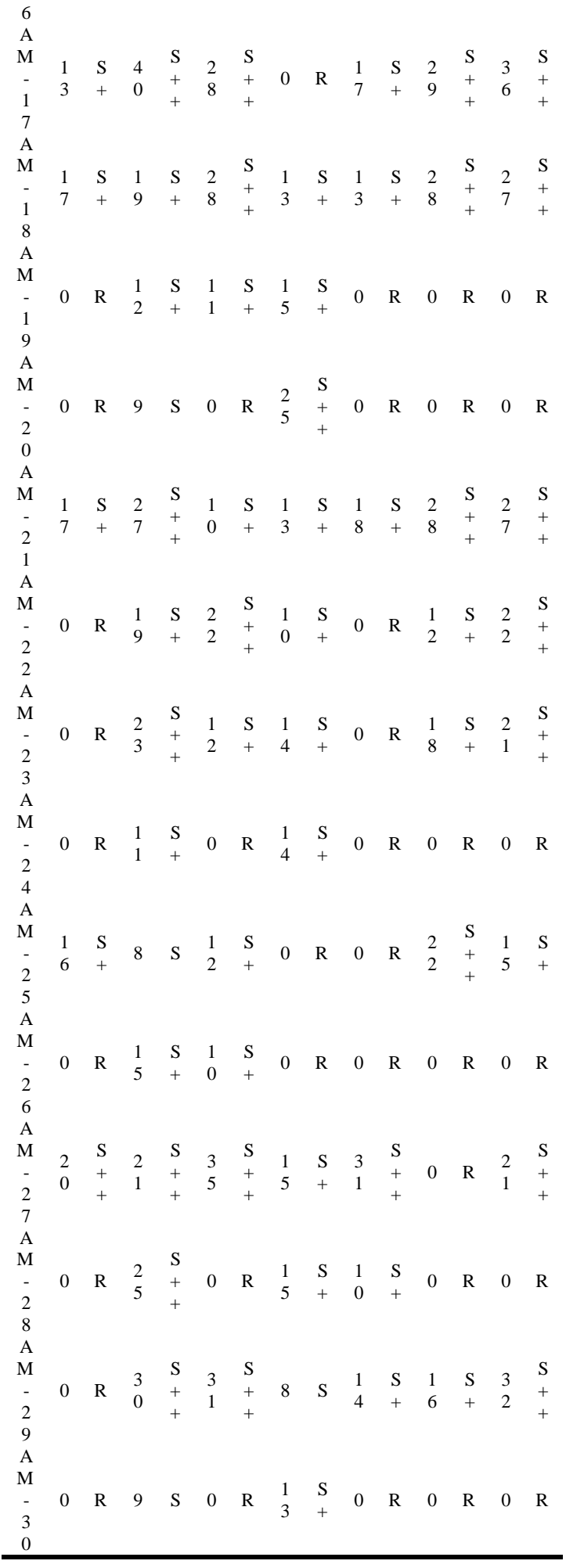

Abbreviations: Resistant (R); weakly sensitive (S); moderate sensitive (S+); Highly Sensitive $(\mathrm{S}++)$; Diameter $(\mathrm{mm})$ of Zone around Antibiotic (D/Z).

\section{In vitro antagonistic activity of rhizobacterial isolates}

Fusarium is a complex genus of ascomycete fungi that consists of plant pathogens of agricultural relevance. Controlling Fusarium infection in crops that leads to substantial yield losses is challenging. These economic losses along with environmental and human health concerns over the usage of chemicals in attaining disease control are shifting focus toward the use of biocontrol agents for effective control of phytopathogenic Fusarium spp. Therefore, Antagonistic activity between rhizobacterial isolates and three of the most common phytopathogen ( $F$. solani, $F$. oxysporium and $R$. solani) were examined by dual culture test. In vitro screening revealed a considerable diversity of antagonism as shown in Table (3) and Figure (2 and 3). Generally, most isolates were significantly reduced mycelial growth of $F$. solani by forming an inhibition zone except (AM-11, AM-16, AM-20, AM-21, AM-22, AM-25, AM-28, AM-29 and AM-30). The largest inhibition zone was observed with AM-27 (62\%). Regarding F. oxysporium, all isolates could significantly reduce the mycelial growth except isolates $\mathrm{AM}-23, \mathrm{AM}-25$ and $\mathrm{AM}-28$ that showed no antagonistic effects against mycelium growth of this phytopathogen. It was remarkable that isolate AM-12 was more effective by $60 \%$ inhibition of mycelial growth of $F$. oxysporium in dual culture test. Concerning the last phytopathogen ( $R$. solani) all isolates showed a considerable reduction mycelial growth of this phytopathogen except three isolates AM-1, AM-3 and AM-11. Thus, the isolate AM-11 showed no antagonistic effects against mycelium growth of $F$. solani and $R$. solani together while the same isolate revealed low antagonism against mycelium growth of $F$. oxysporium used in the present work. In the same manner, isolates AM-25 and AM-28 showed no antagonistic effects against mycelium growth of $F$. solani and $F$. oxysporium while they showed low antagonism against mycelium growth of $R$. solani.

Out of the 30 isolates, four (AM-7, AM-12, AM-26, and AM27) showed high antagonistic activity against mycelium growth of all phytopathogens without exception. In addition, isolates AM-1, AM-3, AM-4, AM-6, AM-12 and AM-27 strongly inhibited the growth of F. solani by 50, 57, 51.5, 58, 55.5 and $62 \%$ respectively, while isolates AM-3, AM-5, AM-7, AM-12, AM-14, AM-18 and AM-26 showed a good degree of antagonistic activity against $F$. oxysporium $(55.5,55.5,50,60$, $50,56.5$ and $55 \%$, respectively). Similarly, isolates AM-7, AM9 and AM-24 exhibited a perfect behavior of antagonistic activity against R. solani by $56.5,55.5$ and $50 \%$, respectively, while isolate AM-15 exhibited temperate antagonistic activity (45.5, 45 and 45.5\%, respectively) against all phytopathogens. Based on the results of in vitro assays four strains AM-7, AM12, AM-26 and AM-27 were found to have inhibitory activity more than $40 \%$ and those were selected for future experiments.

Similar results were reported from the rhizospheric bacteria in sugar beet plants by Karimi et al. [19], who found that 21 rhizobacterial isolates exhibited antagonistic activity against two strains of Rhizoctonia solani (Rs 124 and Rs 133). In dual culture assay of 75 endophytic bacterial strains of sugar beet, 19 strains could inhibit Aphanomyces cochlioides, and 23 showed antagonistic activity toward Phoma betae, four to Pythium ultimum, and 53 to $R$. solani [49].
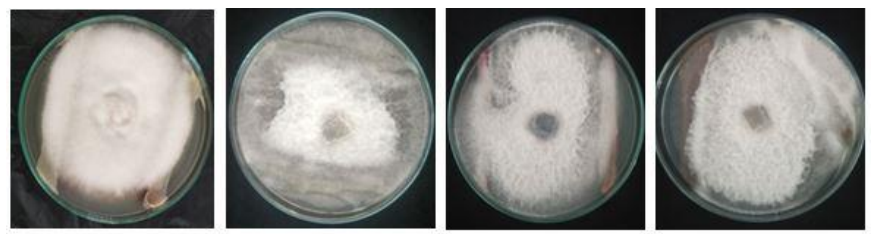

Figure (2): Positive control displaying the negative antagonistic activity of some rhizospheric bacterial isolates in the dual culture inoculation 


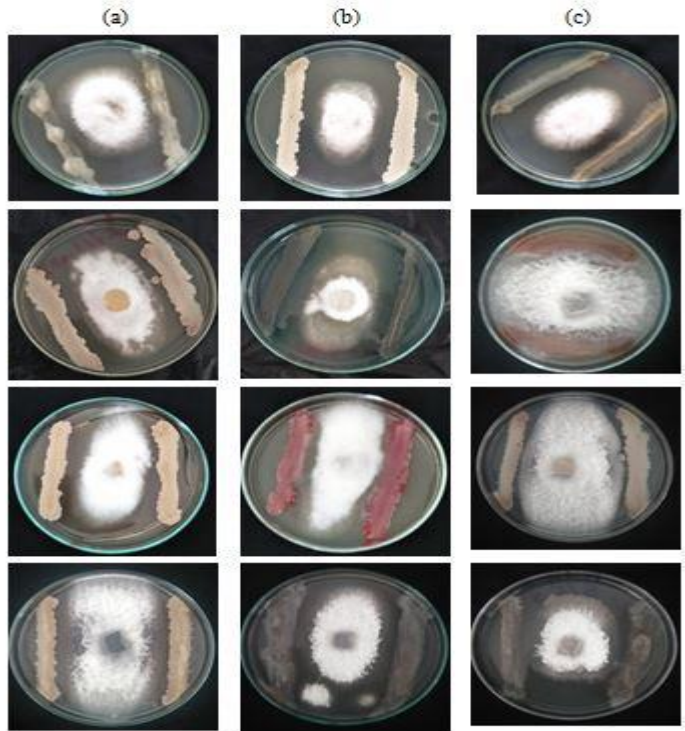

Figure (3): Inhibition effect of some bacterial isolates against: (a) R. solani; (b) F. solani and (c) F. oxysporium.

Table (3): Comparative performance of rhizospheric bacterial isolates in percentages of mycelia growth inhibition of phytopathogenic fungi using agar streak method.

\begin{tabular}{cccc}
\hline & \multicolumn{3}{c}{ Phytopathogens } \\
\cline { 2 - 4 } Isolates & $F$. solani & $\begin{array}{c}F . \\
\text { oxysporium }\end{array}$ & R. solani \\
\hline AM-1 & 50.0 & 48.5 & 00.0 \\
AM-2 & 37.0 & 12.0 & 08.5 \\
AM-3 & 57.0 & 55.5 & 00.0 \\
AM-4 & 51.5 & 20.0 & 16.5 \\
AM-5 & 25.0 & 55.5 & 33.0 \\
AM-6 & 58.0 & 35.0 & 28.5 \\
AM-7 & 44.0 & 50.0 & 56.5 \\
AM-8 & 33.0 & 40.0 & 11.0 \\
AM-9 & 51.0 & 11.0 & 55.5 \\
AM-10 & 35.0 & 40.0 & 40.5 \\
AM-11 & 00.0 & 37.0 & 00.0 \\
AM-12 & 55.5 & 60.0 & 45.0 \\
AM-13 & 20.0 & 46.5 & 20.0 \\
AM-14 & 36.0 & 50.0 & 39.0 \\
AM-15 & 45.5 & 45.0 & 45.5 \\
AM-16 & 00.0 & 34.0 & 33.0 \\
AM-17 & 29.0 & 16.0 & 33.0 \\
AM-18 & 33.0 & 56.5 & 33.0 \\
AM-19 & 48.0 & 20.0 & 33.0 \\
AM-20 & 00.0 & 33.0 & 30.0 \\
AM-21 & 00.0 & 26.0 & 22.0 \\
AM-22 & 00.0 & 16.0 & 16.5 \\
AM-23 & 33.0 & 0.0 & 25.0 \\
AM-24 & 28.0 & 33.0 & 50.0 \\
AM-25 & 00.0 & 0.0 & 37.5 \\
AM-26 & 46.5 & 55.0 & 43.0 \\
AM-27 & 62.0 & 40.0 & 40.0 \\
AM-28 & 00.0 & 0.0 & 32.0 \\
AM-29 & 00.0 & 23.0 & 33.0 \\
AM-30 & 00.0 & 22.0 & 44.0 \\
\hline LSD & 01.1 & 1.6 & 2.2 \\
(0.05) & & & \\
\hline
\end{tabular}

Values are the mean of 3 replicates; the formula for PIRG is as follows: $\mathrm{L}(\%)=$ $[(\mathrm{C}-\mathrm{T}) / \mathrm{C}] \times 100$

\section{Genetical Identification of bacterial strains using 16S rRNA}

Partial-length of 16S rRNA gene ( $1200 \mathrm{bp})$ was successfully amplified from four isolates (Fig. 4). Unfortunately, two of them (AM-15 and AM-26) were successfully sequenced. Nucleotide BLAST of the AM-26 16S rRNA showed the highest similarity to many Pseudomonas chlororaphis subsp. aurantiaca strains [e.g., strain ARS (ACNO CP045221.1); strain ARS (ACNO KJ094432.1); strain B-162 (ACNO CP050510.1); strain zm-1 (ACNO CP048051.1); strain BT59
(ACNO MN203735.1); strain ST-TJ4 (ACNO MT110678.1) and strain LPB0287 (ACNO MN577297.1)]. A highest similarity to other different Pseudomonas chlororaphis strains [e.g., strain ESR15 (ACNO MN173423.1); strain Pb-St2 (ACNO CP027716.1); strain PB-St2 (ACNO EU761590.1); strain A54 16S (ACNO MT280204.1); strain DST27 (ACNO MT163397.1) and strain JZY2-25 (ACNO MT071368.1)] were also observed. In addition. many other of strains Pseudomonas sp. showed a very high degree of similarity (> 99.5\%) to the present AM-26 16S rRNA sequence.

In agreement, most pseudomonas isolated from the plant rhizosphere favor the growth of plants through direct and indirect mechanisms. These bacteria produce phytohormones that promote plant growth and produce secondary metabolites that inhibit the growth of pathogenic bacteria and fungi, ensuring crop health. Pseudomonas chlororaphis subsp. aurantiaca strain Pa40, was isolated during an investigation aimed to identify biocontrol agents for Rhizoctonia cerealis [50]. This strain exhibited clear and consistent suppression of wheat sharp eyespot disease in a greenhouse study. It was tested for antibiosis towards various phytopathogens and assayed for many biocontrol activities and plant- beneficial traits. Likewise, the bacterial biocontrol agent Pseudomonas chlororaphis subsp. aurantiaca strain Pcho10 was selected from more than 1,476 wheat-head-associated bacterial strains according to its antagonistic activity in vitro [51]. Results of this study indicate that this strain has high potential to be developed as a biocontrol agent against F. graminearum. Similarly, Rosas [52] stated the antifungal activity of Pseudomonas aurantiaca SR1 strain against several pathogenic strains, among them, Fusarium, Pythium, Rhizoctonia and Sclerotium spp. The SR1 aurantiaca strain has been shown to be a plant growth promoter for various crops, such as alfalfa, wheat, soybean, maize, carob, sugar cane, as well as promoting germination and obtaining vigorous and healthy seedlings.

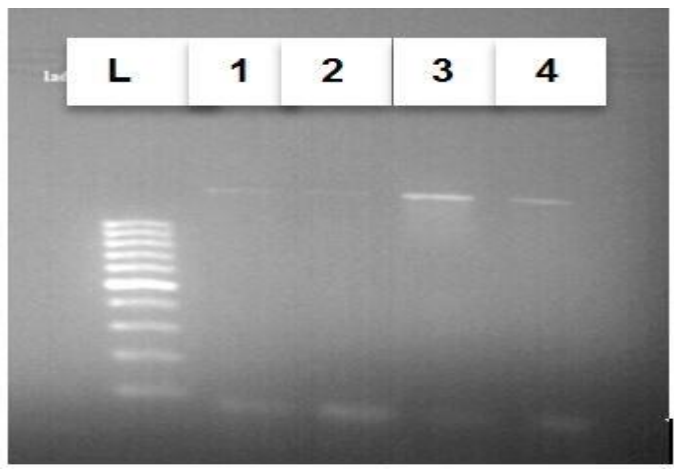

Figure (4): Partial-length of 16S rRNA gene ( $1200 \mathrm{bp})$ amplified from: (1), AM-9; (2), AM-11; (3), AM-15 and (4), AM-26 isolates. (L), is a ladder sequence of $100 \mathrm{bp}$.

Moreover, the antagonistic activity by Pseudomonas fluorescens strain 96.578 on the plant pathogenic fungus Rhizoctonia solani was studied by Nielsen et al., [53]. When challenged with strain 96.578 or purified tensin, Rhizoctonia solani reduced radial mycelium extension but increased branching and rosette formation. They concluded that the antagonistic activity of strain 96.578 towards Rhizoctonia solani was caused by tensin. When coated onto sugar beet seeds, tensin production by strain 96.578 could be of significant 
importance for inhibition of mycelial growth and seed infection by Rhizoctonia solani.

Concerning the bacterial isolate AM-15, the obtained $16 \mathrm{~S}$ ribosomal RNA sequence of shared a high similarity (>99.63\%) with the partial sequence of $16 \mathrm{~S}$ ribosomal RNA gene of Bacillus subtilis strain RRLKE01 (ACNO KF029595.1). High similarity (99.54\%) were also observed with many other Bacillus subtilis strains (e.g., BL-01, CP028812.1; JCL16, CP054177.1, SP1， CP058242.1; CV16, CP062497.1; LBUM979, CP065789.1; NB74, MT534578.1; HFBP08, MT538260.1; 3617, MT538489.1; 3667, MT538531.1 ... etc.). Moreover, different Bacillus sp. strains (e.g., SPB7, MT554518.1; D51, MT579845.1; JM1, MT706000.1; JM3, MT706001.1; ZHX3, MT712262.1 ... etc.). These results strongly suggest the fitting of AM-15 isolate to Bacillus sp. More sequence results specially for some of the housekeeping genes, might be required to family identify this isolate.

In agreement, Bacillus amyloliquefaciens strain BLB369, Bacillus subtilis strain BLB277, and Paenibacillus polymyxa strain BLB267 exhibiting broad spectrum against several phytopathogenic fungi [23]. The tertiary combination of Bacillus cells led to the highest protection rate against $F$. graminearum fungus which could be due to strains synergistic or complementary effects. [54] Analyzed the plant-growth promoting (PGP) and biocontrol attributes of four bacilli (Bacillus simplex $30 \mathrm{~N}-5, B$. simplex 11, B. simplex 237, and $B$. subtilis 30VD-1) against phytopathogenic Fusarium spp. of all the bacilli included in this study, B. subtilis 30VD-1 (30VD-1) demonstrated the most effective antagonism against Fusarium spp. under in vitro conditions. Pea seed bacterization with 30VD-1 led to considerable reduction in wilt severity in plants with about $35 \%$ increase in dry plant biomass over uninoculated plants growing in Fusarium-infested soil.

Likewise, bacteria isolated from wheat kernels and plant anthers were screened for antagonistic activity against $F$. graminearum [22]. Based on its in vitro effectiveness, strain SG6 was selected for characterization and identified as Bacillus subtilis. This strain exhibited a high antifungal effect on the mycelium growth, sporulation and DON production of $F$. graminearum with the inhibition rate of $87.9 \%, 95.6 \%$ and $100 \%$, respectively. Further, ultra-structural examination shows that $B$. subtilis SG6 strain induced stripping of $F$. graminearum hyphal surface by destroying the cellular structure.

Likewise, based on its in vitro effectiveness, Bacillus subtilis strain SG6 was isolated from wheat kernels. This strain exhibited a high antifungal effect against mycelium growth of $F$. graminearum. Further, ultra-structural examination shows that B. subtilis SG6 strain induced stripping of $F$. graminearum hyphal surface by destroying the cellular structure.

\section{REFERENCES}

[1]Chaparro J. M., Badri D. V., Vivanco J. M.: Rhizosphere microbiome assemblage is affected by plant development. ISME J, 2014. 8: 790-803.

[2]Bulgarelli D., Garrido-Oter R., Munch P. C., Weiman A., Droge J., Pan Y., McHardy A. C., and Schulze-Lefert P.: Structure and function of the bacterial root microbiota in wild and domesticated barley. Cell Host Microb 2015, 17: 392-403.
[3]Smith D. L., Gravel V., Yergeau E.: Editorial: signaling in the phytomicrobiome. Front. Plant Sci.2017, 8:611.

[4]Berg G., Rybakova D., Grube M., and Koberl M.: The plant microbiome explored: implications for experimental botany, J. Exp. Bot. 2016, 67 995-1002.

[5]Subba Rao N. S. Soil Microbiology: Fourth Edition of Soil Microorganisms and Plant Growth. Sci. Pub. Inc., USA. pp.1999: 407.

[6]Kloepper JW, Schroth MN Plant growth-promoting rhizobacteria on radishes. In: Proceedings of the 4th international conference on plant pathogenic bacteria. 1978, 2: 879-882.

[7]Manjula K., Kishore G. K., and Podile A. R.: Whole cells of Bacillus subtilis $\mathrm{AF} 1$ proved more effective than cell-free and chitinase-based formulations in biological control of citrus fruit rot and groundnut rust. Canadian journal of microbiology, 2004, 50: 737-744.

[8]Cazorla F. M., Romero D., Pérez-García A., Lugtenberg B. J. J., Vicente A. D., and Bloemberg G.: Isolation and characterization of antagonistic Bacillus subtilis strains from the avocado rhizoplane displaying biocontrol activity. Journal of applied microbiology 2007 , 103: 1950-1959.

[9]Ryu C. M., Farag M. A., Hu,C. H., Reddy M. S., Wei H. X., Paré P. W., and Kloepper J. W: Bacterial volatiles promote growth in Arabidopsis. Proceedings of the National Academy of Sciences, 2003, 100: 4927-4932.

[10]Yasmin S., Bakar M. A., Malik K. A. and Hafeez F. Y: Isolation, characterization and beneficial effects of rice associated plant growth promoting bacteria from Zanzibar soils. Journal of basic microbiology, 2004, 44: 241-52.

[11]Filippi M. C. C., Da Silva G. B., Silva-Lobo V. L., Côrtes M. V. C., Moraes A. J. G., and Prabhu, A. S: Leaf blast (Magnaporthe oryzae) suppression and growth promotion by rhizobacteria on aerobic rice in Brazil. Biological Control 2011, 58: 160-166.

[12]Islam Md R., Madhaiyan M., Boruah H. P, Yim W., Lee G., Saravanan V. S., Qingling Fu, Hu H., Sa T: Characterization of plant growth-promoting traits of free-living diazotrophs and their inoculation effects on growth of rice plant. J Microbiol Biotechnol, 2009, 19: 121322.

[13]Vessey J. K.: Plant growth promoting rhizobacteria as biofertilizers. Plant and soil, 2003, 255: 571-586.

[14]Islam S., Akanda A. M., Prova A., Islam M. T., and Hossain M. M.: Isolation and identification of plant growth promoting rhizobacteria from cucumber rhizosphere and their effect on plant growth promotion and disease suppression. Front Microbiol. 2016, 6: 1360.

[15]Podile A. R., and Kishore G. K.: Plant growth-promoting rhizobacteria. In Plant-associated bacteria, pp. 2007, 195-230: Springer, Dordrecht.

[16]Hallmann J., and Berg G: Spectrum and population dynamics of bacterial root endophytes. In Microbial root endophytes 2006, (pp. 1531): Springer, Berlin, Heidelberg.

[17]FAO STAT: Review of the Egyptian Sugar Sector. 2019, FAOEBRD Cooperation

[18]Cooke D. A., and Scott P. K.: The Sugar Beet Crop: Science into Practice, Chapman and Hall. New York 1993, 195

[19]Karimi E., Safaie, N., Shams-Baksh M., and Mahmoudi B.: Bacillus amyloliquefaciens SB14 from rhizosphere alleviates Rhizoctonia damping-off disease on sugar beet. Microbiological research 2016, 192: 221-230.

[20]Dent B. B., Forbes S. L., and Stuart B. H: Review of human decomposition processes in soil. Environmental Geology 2004, 45: 576-585.

[21]Kiewnick S., B.J. Jacobsen A. Braun-Kiewnick J. L.A. Eckhoff and J.W. Bergman,: Integrated control of Rhizoctonia crown and root rot of sugar beet with fungicides and antagonistic bacteria. Plant Dis. 2001, 85: 718-722.

[22]Zhao Y., Selvaraj J. N., Xing F., Zhou L., Wang Y., Song H., Tan X., Sun L., Sangare L., Folly Y., M., and Liu Y.: Antagonistic action of Bacillus subtilis strain SG6 on Fusarium graminearum, PLoS One. 2014, 9: e92486.

[23]Zalila-Kolsi I., Ben Mahmoud A., Ali H., Sellami S., Nasfi Z., Tounsi S., Jamoussi K.: Antagonist effects of Bacillus spp. strains 
against Fusarium graminearum for protection of durum wheat (Triticum turgidum L. subsp. durum), Microbiological Research 2016, 192: 148-158.

[24]Elmer W. H: Influence of chloride and nitrogen form on Rhizoctonia root and crown rot of table beets. Plant disease 1997, 81: 635-640.

[25]Buttner G., Pfahler B., and Petersen J: Rhizoctonia root rot in Europe-incidence, economic importance and concept for integrated control. 1st. In Joint IIRB-ASSBT Congress. San Antonio, USA 2003, 897-901.

[26]Lugtenberg B., and Kamilova F: Plant-growth-promoting rhizobacteria. Annu. Rev. Microbiol. 2009, 63: 541-556.

[27]Somasegaran P. and Hoben H. J. "Methods in Legume-Rhizobium technology" inHandbook for Rhizobia. NewYork: Springer-Verlag 1994, 332-341.

[28]Vincent J. M., and Humphrey B: Taxonomically significant group antigens in Rhizobium. J. Gen. Microbial. 1970, 63: 379-382.

[29]McFaddin J. F: Biochemical tests for identification of medical bacteria. 3rd ed. Baltimore, Lippincott Williams and Wilkins. 2000, p 912.

[30]Berkhoff H. A. and Vinal A. C: Congo red medium to distinguish between invasive and non-invasive Escherichia coli pathogenic for poultry. Avian diseases 1986, 117-121.

[31]Pikovskaya R. I: Mobilization of phosphorus in soil in connection with vital activity of some microbial species. Mikrobiologiya.1948, 17: 362-370.

[32]Clower C. and Hay K: Experiments in Microbial genetics. Blackwell Scientific Publishers, UK. 1968, 232-233.

[33]Dela Cruz T. E. E., and Torres J. M. O. 2012: Gelatin hydrolysis test protocol.

[34]Lal A., and Cheeptham N. 2012: Starch agar protocol.

[35]Sun L., Lu, Z., Bie X., Lu, F., and Yang, S: Isolation and characterization of a co-producer of fengycins and surfactins, endophytic Bacillus amyloliquefaciens ES-2, from Scutellaria baicalensis Georgi. World Journal of Microbiology and Biotechnology. 2006, 22: 1259-1266.

[36]Rapindran R., and Vidhyasekaran P: Development of a formulation of Pseudomonas fluorescens PfALR2 for management of rice sheath blight. Crop protection. 1996, 15: 715-721.

[37]Patel H. A., Patel R. K., Khristi S. M., Parikh K., and Rajendran G: Isolation and characterization of bacterial endophytes from Lycopersicon esculentum plant and their plant growth promoting characteristics. Nepal Journal of Biotechnology 2012, 2: 37-52.

[38]Altschul S. F., Madden, T. L., Schäffer, A. A., Zhang, J., Zhang, Z., Miller, W., and D. J. Lipman. Gapped BLAST and PSI-BLAST: A new generation of protein database search programs. Nucleic Acids Research. 1997, 25: 3389-3402.

[39]Garbeva P., Van Veen J. A., and Van Elsas J. D: Predominant Bacillus spp. in agricultural soil under different management regimes detected via PCR-DGGE. Microbial Ecology. 2003, 45: 302-316.

[40]Czaban J., Gajda A., and Wróblewska B: The motility of bacteria from rhizosphere and different zones of winter wheat roots. Pol. J. Environ. Stud. 2007, 16: 301-308.
[41]Ngomle S., Bhattacharya P. M., Roy A., and Ambesh B. S: Isolation and screening of phosphate solubilizing Bacteria from different crop rhizosphere. The Ecoscan 2014, 6: 505-509.

[42]Modi K., and Patel P: Isolation and characterization of plant growth promoting rhizobacteria associated with Saccharum officinarum L. Curr Synthetic Sys Biol., 2017, 5: 2332-2737.

[43] Yousten A. A., Johnson J. L., and Salin, M. A: Oxygen metabolism of catalase-negative and catalase-positive strains of Lactobacillus plantarum. Journal of bacteriology, 1975, 123: 242-247.

[44]Fouts D. E., Tyler H. L., DeBoy R. T., Daugherty S., Ren Q., Badger J. H., and Dodson R. J: Complete genome sequence of the N 2fixing broad host range endophyte Klebsiella pneumoniae 342 and virulence predictions verified in mice. PLoS Genet, 2008, 4: e1000141. [45]Mbai F. N., Magiri E. N., Matiru V. N., Nganga J., and Nyambati, V. C. S: Isolation and characterization of bacterial root endophytes with potential to enhance plant growth from kenyan basmati rice. American International Journal of Contemporary Research, 2013, 3: $25-40$

[46]Wani P.A., A. Zaidi and M.S. Khan: Chromium reducing and plant growth promoting potential of Mesorhizobium species under chromium stress. Bioremediation J., 2009, 13: 121-129.

[47]Silver S., and Misra T. K: Plasmid-mediated heavy metal resistances. Annual Reviews in Microbiology, 1988, 42: 717-743.

[48]Wani P. A., and Irene O. I: Screening of microbes for their metal, antibiotic resistance and plant growth promoting activity. Current Research in Bacteriology, 2014, 7: 22-31.

[49]Zachow C., Tilcher R., and Berg G: Sugar beet-associated bacterial and fungal communities show a high indigenous antagonistic potential against plant pathogens. Microbial ecology, 2008, 55: 119-129.

[50]Jiao Z., N. Wu L. Hale W. Wu D. Wu and Y. Guo: Characterization of Pseudomonas chlororaphis subsp. aurantiaca strain Pa40 with the ability to control wheat sharp eyespot disease. Analysis of Applied Biology 2013, 163: 444-453.

[51]Hu W., Gao Q., Hamada M. S., Dawood D. H., Zheng J., Chen Y., and Ma Z: Potential of Pseudomonas chlororaphis subsp. aurantiaca strain Pcho10 as a biocontrol agent against Fusarium graminearum. Phytopatholog y2014, 104: 1289-1297.

[52]Rosas S. B: Pseudomonas chlororaphis subsp. aurantiaca SR1: isolated from rhizosphere and its return as inoculant. International Biology Review, 2017, 1: 1 of 19 .

[53]Nielsen T. H., C. Thrane, C. Christophersen, U. Anthoni and J. Sørensen: Structure, production characteristics and fungal antagonism of tensin - a new antifungal cyclic lipopeptide from Pseudomonas fluorescens strain 96.578. Journal of Applied Microbiology Journal of Applied Microbiology, 2000, 89: 992-1001.

[54]Khan N., Martínez-Hidalgo P., Ice T. A., Maymon M., Humm E. A., Nejat N., Sanders E. R., Kaplan D., and Hirsch A. M : Antifungal activity of Bacillus species against Fusarium and analysis of the potential mechanisms used in biocontrol, Front Microbiol. 2018, 9 : 2363. 